$$
\begin{aligned}
& \text { NAG } 5-913 \\
& 1 N-43-C / 2 \\
& 311007 \\
& P 19
\end{aligned}
$$

\title{
A Comparison of Surface Sensible and Latent Heat Fluxes from Aircraft and Surface Measurements in FIFE 1987
}

\author{
Robert D. Kelly \\ Department of Atmospheric Science \\ University of Wyoming \\ P.O. Box 3038 \\ Laramie, WY 82071-3038 \\ Eric A. Smith \\ Department of Meteorology \\ Florida State University \\ Tallahassee, FL 32306 \\ J. Ian MacPherson \\ National Research Council \\ Building U61, Montreal Road \\ Ottowa, Ontario \\ Canada K1A OR6
}

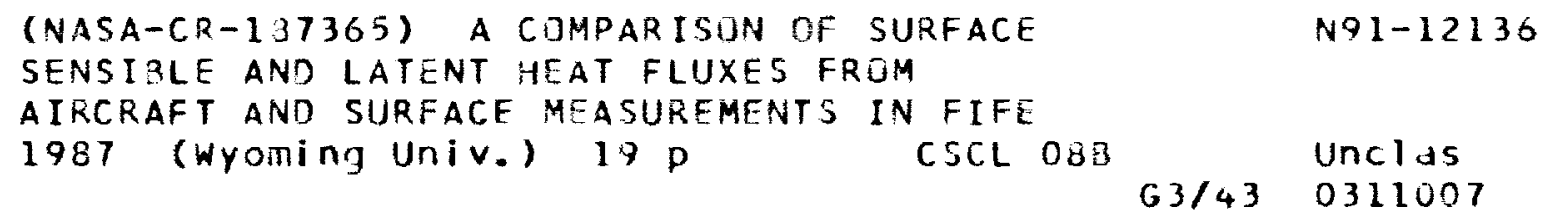




\begin{abstract}
Surface fluxes of sensible and latent heat over a tall-grass prairie in central Kansas, as measured by 22 surface stations during FIFE 1987, are compared with values gained indirectly by linear extrapolation of aircraft-measured flux profiles to the surface. The results of 33 such comparisons covering the period 26 June to 13 October 1987 indicate that 1) the sensible heat flux profiles were generally more linear with less scatter in the measurements at each level than were the latent heat flux profiles, 2) the profile extrapolations of sensible heat flux in general underestimate the surface averages by about $30 \%$, with slightly better agreement during periods of small flux, and 3 ) the profile extrapolations of latent heat flux in general underestimate the surface averages by about $15 \%$, with overestimates during periods of small fluxes (dry conditions) and overestimates during periods of large fluxes (moist conditions). Possible origins of the differences between the two sets of measurements are discussed, as directions for further research.
\end{abstract}




\section{Introduction}

During the First ISLSCP Field Experiment (FIFE), which concentrated surface, airborne, and satellite measurements over a 15x15 km area of tall-grass prairie in central Kansas (Sellers $e t$ al., 1988), an important objective was to compare fluxes of sensible and latent heats as measured at the surface and in the boundary layer (BL). To that end, surface and airborne flux data were collected during four Intensive Field Campaigns (IFCs) in 1987. The IFCs were spaced over the growing season in order to cover a complete cycle of vegetative change from "first greenness" in the spring to senescence in the fall, and covered the periods 26 May-6 June, 25 June-11 July, 6-21 Aug., and $5-16$ Oct.

To gather the flux measurements, 22 surface stations were distributed across the FIFE site, with 6 using the eddy correlation method with instrumentation at $2 \mathrm{~m}$ agl, and 16 using the Bowen ratio method, again with instrumentation at $2 \mathrm{~m}$ agl. At the same time, several twin-engine turboprop aircraft were used for eddy correlation flux measurements in the BL.

The purpose of this paper is a comparison of fluxes measured at the surface, presented as site-wide and time averages of the data collected at the surface stations, with values extrapolated to the surface from BL flux profiles determined by the aircraft. These extrapolations were done by simple linear regression, based on aircraft fluxes measured over repeated, constant-altitude flights at 2-4 levels in the BL. In all, 33 profiles were analyzed for the period 26 June-13 Oct., 1987, which encompasses IFCs 2-4, using data collected by the Canadian National Research Council Twin Otter (TW) and the University of Wyoming King Air (KA) research aircraft. The surface data corresponding to the times of the aircraft profiles were taken from the continuous set of surface data, and represent measurements by Florida State University, the University of Nebraska, xxx, xxx, xxx.

Three of the days for which comparisons are presented in this paper have previously been examined with different methods by Betts et al. (1990, hereafter referred to as B90). For these cases (20 Aug., and 8 and 13 Oct.) the aircraft data were collected in a pattern allowing full analysis of the BL budgets for sensible and latent heats. In each case, linear extrapolation of the eddy correlation 
flux profiles to the surface gave underestimates of the surface fluxes, as represented by site-wide averages of the surface data. Surface sensible heat fluxes were generally underestimated by about $40 \%$, and surface latent heat fluxes by about $30 \%$. As discussed by B 90 , the error in the extrapolations may be attributed to several sources, including 1) underestimation of the large-eddy, or longwavelength, contribution to the BL fluxes, due to the relatively short $(15 \mathrm{~km})$ flight paths used in FIFE, and 2) underestimation of the long-wavelength contribution due to the 5-km cutoff, highpass filter applied to the aircraft data before calculation of the fluxes. Special flights were included in the 1989 FIFE operations to explore both of these possibilities. In addition, since the publication of that paper, the surface sensible heat flux measurements from the 16 Bowen ratio sites have been revised downward by about $10-15 \%$, after it was found that many of the net radiation flux instruments used at those sites in 1987 had overestimated the long-wavelength radiative fluxes.

Thus, the comparisons presented here differ from those of B90 in that the revised surface flux data were used, and all the available aircraft profiles from 1987 have been included. Data from the cases analyzed by B90 were treated in the same way as the other profiles, i.e., surface fluxes were predicted by linear regression.

\section{Data collection and processing}

The following two sections describe the collection and processing techniques used for the two sets of data compared in section 3. Description of the instruments themselves, both for the surface sites and for the two aircraft, may be found in the following publications: Betts et al. (1990), XXX.

\subsection{Surface flux measurements}

At each of the 22 surface stations, which were distributed over the $15 \times 15 \mathrm{~km}$ FIFE area, fluxes were recorded every 30 minutes, at 15 and 45 minutes past each hour, as averages of the previous $\mathrm{xx}$ minutes of flux measurement. (See $\operatorname{xxxxx}(19 \mathrm{xx})$ for a description of the method of site selection and a map of the exact station locations.) For the time periods used in this study, which correspond to the times one or both of the aircraft were over the site measuring the BL flux profiles, 
an average of 20 stations successfully reported surface flux data (range 15-22). To obtain surface flux values for comparison with the aircraft extrapolations, simple arithmetic means were calculated from all the reported fluxes at each reporting time during which an aircraft was present. These areaaverages were in turn averaged over the number of reporting times during which an aircraft was present (2-5 times per profile). Thus, the surface values given below are labeled time-area averages. In addition, the maximum and minimum area-averages while an aircraft was present were determined for each case.

\subsection{Aircraft flux measurements}

As described by B90, data used in the eddy correlation measurements by the Twin Otter were sampled at $16 \mathrm{~Hz}$, then low-pass filtered at $5 \mathrm{~Hz}$, and high-pass filtered at $0.012 \mathrm{~Hz}$. This preserved data for spatial scales from about $10 \mathrm{~m}$ to $5 \mathrm{~km}$ for an aircraft speed of $50 \mathrm{~m} \mathrm{~s}^{-1}$. Correspondingly, the King Air data were sampled at $10 \mathrm{~Hz}$, then low-pass filtered at $2 \mathrm{~Hz}$, and high-pass filtered at $0.017 \mathrm{~Hz}$, preserving data for spatial scales from about $40 \mathrm{~m}$ to $5 \mathrm{~km}$ for an aircraft speed of $85 \mathrm{~m}$ $\mathrm{s}^{-1}$. The 5-km high-pass filters $(0.012 \mathrm{~Hz}$ for TW and $0.017 \mathrm{~Hz}$ for $\mathrm{KA})$ were used in FIFE in an effort to avoid problems associated with undersampling wavelengths longer than $5 \mathrm{~km}$ when using only a $15 \mathrm{~km}$ flight path.

As mentioned above, profiles of the eddy correlation fluxes were studied for cases in which repeated constant-altitude flight segments had been flown at 2-4 different levels in the BL. As FIFE progressed in 1987, the pattern in which these segments were flown was changed. This resulted in three general patterns for obtaining profiles: 1) a single "stack" of level segments, with 2-6 passes at each level and all at the same azimuthal orientation, 2) a stack of " $L$ " shaped, constant altitude passes, with 2-4 passes at each of 2-4 levels, and 3) a double stack of level segments at constant orientation, with one stack along the north edge and the other along the south edge of the site, giving 4-6 passes at each of 2-4 levels. In addition, and also as a progression of experimental design in 1987 , some of the stacks were flown in a sequence allowing removal of linear time trends in the data (B90); these are referred to here as "time-centered" cases. In the analysis presented here all profiles 
were processed in the same manner, regardless of whether or not the data had been collected in a time-centered pattern.

Figs. 1 and 2 show examples of aircraft profiles for sensible heat flux $\left(\mathrm{F}_{\mathrm{H}}\right)$ and latent heat flux $\left(F_{E}\right)$ for two cases, one from a period of abundant soil moisture and active plant growth (6 July), and the other from a period of dry soil and vegetative senescence ( 8 Oct.). The surface data are shown in the figures as open boxes. The dot in each box is the time-area average flux, and the left and right limits of each box are the minimum and maximum area averages for that case (see above). The regression lines for both the sensible and latent heat fluxes are also shown. The solid boxes in the figure show the ranges of predicted surface values from $\mathrm{F}_{0}-\sigma$ to $\mathrm{F}_{0}+\sigma$ for each regression, where $F_{0}$ is the predicted surface flux. The error, or standard deviation, of the flux estimate at the surface was calculated as

$$
\sigma\left(F_{0}\right)=\frac{s}{\sqrt{n}}\left[1+\left(\frac{h_{0}-\bar{h}}{s_{h}}\right)^{2}\right]^{1 / 2}
$$

In this expression (Morris and Rolph 1981) $\mathrm{h}_{0}$ is the surface pressure altitude, $\bar{h}$ is the average pressure altitude for the $\mathrm{n}$ data points in the regression, $\mathrm{s}_{\mathrm{h}}$ is the standard deviation of $\mathrm{h}$, and $\mathrm{s}$ is the standard error of the regression.

One of the most striking features of the two cases is the reversal of profiles: Latent heat fluxes were almost three times the sensible heat fluxes on $6 \mathrm{July}$, and about half the sensible heat fluxes on 8 Oct., reflecting changes in soil moisture and in the level of plant activity. Also note that the predicted surface sensible heat flux, $\mathrm{F}_{\mathrm{H} 0}$, is smaller than even the range of surface averages for 8 Oct. A similar under-prediction is seen for the 6 July surface flux of latent heat. The scatter of data points at each level on the profiles is typical of the FIFE BL data, and reflects, at least in part, the time changes that occurred during a period of BL sampling (about $1.5 \mathrm{hr}$ on 6 July and about 2.25 hr on 8 Oct.). A more quantitative indication of the amount of scatter and the degree of linearity 
for each profiles is the correlation coefficient, $r$, of the linear regression (see Tables 1 and 2 ). On 6 July r was 0.71 and 0.27 (for the sensible and latent heat fluxes, respectively), while on 8 Oct. it was 0.95 and 0.94 .

\section{Results}

Results of the surface averaging and profile regression are summarized in Tables 1 and 2. Entries in these tables for the BL profiles include the number of passes and flight levels used in constructing the profile, whether or not the flight pattern was time-centered, the correlation coefficient of the linear regression, and the $F_{0}$ and $F_{0} \pm \sigma$ values for each prediction of surface fluxes. Entries for the surface measurements include the minimum, average, and maximum for the site-wide average fluxes measured during each aircraft profile, the number of sites reporting, and the number of reporting times for each case. The 14 Aug. values for latent heat fluxes are considered anomalous and are not included in the analysis and conclusions presented below.

Several patterns are noted in these summaries. First, the correlation coefficients for the flux profiles (r) are were different for the sensible and latent heat cases. For the sensible heat fluxes, $22 / 33$ cases had $r \geq 0.7$ and $16 / 33$ had $r \geq 0.8$. In contrast, the corresponding fractions for the latent heat fluxes were $4 / 24$ and $2 / 24$, respectively. Thus the sensible heat flux profiles were generally more linear with less scatter in the measurements at each level than were the latent heat flux profiles.

A second pattern visible in the $\mathrm{r}$ values concerns changes with season. In the sensible heat data $\mathbf{r}$ was slightly higher for the October cases than for the June-August cases. For the latent heat data there were not any changes in $r$ from the beginning to the end of the analysis.

The third pattern in these data results from comparing the $\mathrm{F}_{0}$ and surface average values, i.e., by examining the ratio $\mathrm{F}_{0}$ :(surface average) for each case. For the sensible heat fluxes this ratio averaged about 0.71 , and did not change noticeably with IFC or season. Thus, the profile extrapolations were nearly all underestimates of the surface averages by about $30 \%$. In contrast, the same ratios for the latent heat fluxes averaged 0.85 (mostly underestimates) in June-August, when the fluxes 
ranged over $230-443 \mathrm{~W} \mathrm{~m}^{-2}$, but averaged 1.71 (consistent overestimates) in October, when the fluxes ranged over $30-70 \mathrm{~W} \mathrm{~m}^{-2}$.

The profile estimates of surface fluxes are plotted against the surface averages in Figs. 3 and 4, showing graphically some of the patterns noted above. In Fig. 3, for the sensible heat fluxes, all the entries but 4 are to the right of the 1:1 line (dotted), indicating an underestimate of surface values by extrapolation of profiles to the surface. Note, also, that there was apparently little difference between the two aircraft in this regard. The estimates were slightly better during the smaller fluxes of IFC 2 than during the larger fluxes of IFCs 3 and 4. In Fig. 4, for latent heat fluxes, the entries are generally closer to the 1:1 line, with overestimates in IFC 4 and underestimates in IFCs 2 and 3.

\section{Conclusions}

As noted above, the sensible heat flux profiles were generally more linear with less scatter in the measurements at each level than were the latent heat flux profiles. Possible explanations here include the fact that latent heat fluxes (as derived from fluxes of water vapor) are generally more difficult to measure from an aircraft than sensible heat fluxes and thus more scatter may be expected in the data. This difference in the character of the profiles also raises the question of whether or not there is a physical or biophysical explanation of why water vapor fluxes might have varied more widely with time within a given time interval over the FIFE site than did sensible heat fluxes.

In all, the comparisons presented here point clearly to the differences between the aircraft profile predictions and surface measurements of surface sensible heat flux, and show that these differences were quite consistent throughout the FIFE operations of 1987. The recent downward revision of sensible heat flux values for most of the surface stations is reflected in the average $30 \%$ underestimate for the 33 cases given here, compared to the $40 \%$ underestimate described by B 90 . However, the exact origins of the remaining differences are still unclear. As stated by B 90 , they may be a result of undersampling of large-eddy contributions to the total flux and/or a result of the filtering applied to the data. In addition, the simple arithmetic averages of the surface measurements may 
be biased by differences in vegetation, terrain, and soil characteristics at each site. To our knowledge FIFE is one of the first extensive comparisons of aircraft estimates of these fluxes with surface measurements. It may well be that the measurement techniques used on all the surface and airborne platforms need to be reexamined.

Finally, although there is more scatter in the latent heat flux data forming the aircraft profiles than in the sensible heat data, the estimates of surface latent heat fluxes using aircraft profiles were in general underestimates of the surface averages by only about $15 \%$ for the 1987 FIFE cases (B90 found underestimates of about $30 \%$ ). Imbedded within this result is the fact that small values of latent heat flux were overestimated, while the larger values were generally underestimated. This change in the nature of the prediction certainly points to a need to reexamine the platforms and the analysis techniques used for both the surface and the airborne data.

\section{Acknowledgements}

R. D. Kelly was supported by NASA-GSFC under Contract NAG-5-913. He wishes to thank E. Gasaway, G. Gordon, and K. Chartier for their efforts in the field, and S. Allen for drafting the figures. The enthusiastic cooperation of all FIFE participants is gratefully acknowledged.

E. A. Smith ...

J. I. MacPherson ...

\section{References}

Betts, A. K., R. L. Desjardins, J. I. MacPherson, and R. D. Kelly, 1990: Boundary-layer heat and moisture budgets from FIFE. Bound.-Layer Meteor., 50, 109-137.

Morris, C. N., and J. E. Rolph, 1981: Introduction to Data Analysis and Statistical Inference. Prentice-Hall, $389 \mathrm{pp}$.

Sellers, P. J., F. G. Hall, G. Asrar, D. E. Strebel, and R. E. Murphy, 1988: The First ISLSCP Field Experiment (FIFE). Bull. Amer. Meteor. Soc., 69, 22-27. 


\section{Figure captions}

Fig. 1. Aircraft and surface flux measurements, 6 July 1987, 1117-1253 LT. Aircraft data points are pass-averages for sensible heat (circles) and latent heat (+) fluxes, with regression lines extended to the surface. Solid boxes at surface show ranges of regressed flux estimates. Open boxes near surface show mean (dot) and minimum-to-maximum range of surface area-wide averages.

Fig. 2. Same as Fig. 1, for 8 October 1987, 1314-1534 LT.

Fig. 3. Scatter diagram of surface sensible heat fluxes derived from aircraft profiles (abscissa) vs. average sensible heat fluxes measured at the surface (ordinate), including both Twin Otter (TW) and King Air (KA) data from IFCs 2-4 in 1987. Symbols denoting aircraft and IFC are defined in the diagram. Linear regressions are shown for the two aircraft data sets together (TW, KA; solid line), and for each set separately (KA, dash-dot; TW, dashed). Dotted line is $1: 1$ slope.

Fig 4. Same as Fig. 3, but including Twin Otter and surface data only. 


\begin{tabular}{|c|c|c|c|c|c|c|c|c|c|c|c|c|c|c|c|c|c|}
\hline & 总 & $m$ & N & $\left.\right|^{\sigma}$ & 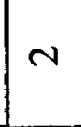 & $\left.\right|^{m}$ & $m$ & $m$ & + & $m$ & $m$ & $m$. & † & $\sim$ & + & \\
\hline & & 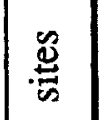 & i & i & i & $\stackrel{\infty}{\sim}$ & ন & 8 & i & $\approx$ & $\cong$ & 2 & $\vec{\sim}$ & $\Rightarrow$ & $\therefore$ & $\therefore$ & \\
\hline \multirow{3}{*}{ 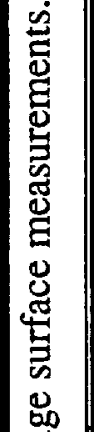 } & & 曽 & $\stackrel{\infty}{\approx}$ & $\mathscr{8}$ & 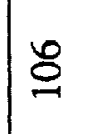 & & ‡ & $\infty$ & 2 & $\Xi$ & $\stackrel{乛}{~}$ & $\Xi$ & $\stackrel{8}{\text { I }}$ & त్ & ల్ల & $\Xi$ & \\
\hline & & $\left|\begin{array}{c}0.0 \\
\frac{\partial}{\sigma}\end{array}\right|$ & $\Xi$ & 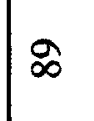 & $\infty$ & 8 & $\Phi$ & $\because$ & $\approx$ & 8 & 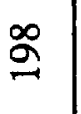 & 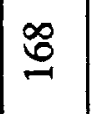 & \&े & ָ̊ & $\underset{\pi}{\infty}$ & $\Xi$ & \\
\hline & & 完 & $\Xi$ & I & $\stackrel{m}{2}$ & $\vec{\sigma}$ & $\approx$ & 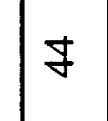 & $\mathscr{B}$ & $\infty$ & $\stackrel{\infty}{\stackrel{\infty}{\sim}}$ & $\vartheta$ & 志 & 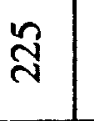 & $\ddot{z}$ & $\vec{\Phi}$ & \\
\hline & 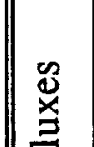 & \begin{tabular}{|l|}
0 \\
0 \\
0 \\
至 \\
\end{tabular} & in & $\approx$ & 18 & 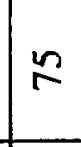 & $\bar{s}$ & $\mid \begin{array}{l}\mid \vec{\infty} \\
\mid\end{array}$ & $\Xi$ & 总 & $\mathbb{Z}$ & $\underset{\mathbb{Z}}{\infty}$ & 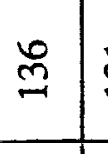 & $\vec{m}$ & $\tilde{s}$ & $\stackrel{\infty}{\simeq}$ & \\
\hline & $\mid \frac{5}{\dot{m}}$ & 운 & in & in & कo & 18 & $\alpha$ & $m$ & $F$ & $\vec{a}$ & $\stackrel{\infty}{\stackrel{\infty}{\sim}}$ & $\vec{\Phi}$ & $\Xi$ & $\Xi$ & $\overrightarrow{\widetilde{\pi}}$ & 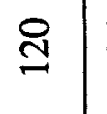 & \\
\hline & 离 & \begin{tabular}{|l|} 
\\
$\vdots$ \\
悹 \\
\end{tabular} & $\approx$ & in & 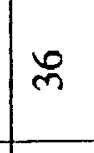 & 8 & $\infty$ & 8 & $F$ & $F$ & \& & $\approx$ & $\approx$ & $\stackrel{1}{\varrho}$ & 离 & 1 & \\
\hline & & r & I & | & $1=$ & f & F. & $\infty$ & דִ & $\because$ & \$. & $\approx$ & $\underset{.}{\infty}$ & $\hat{n}$ & $\vec{\sigma}$ & $\vec{\infty}$ & \\
\hline & 弟 & 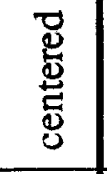 & $\stackrel{8}{\Xi}$ & : & ஜ & 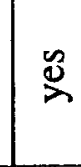 & 음 & 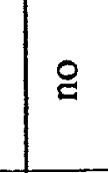 & $\Phi_{\Perp}^{\mathscr{D}}$ & : & 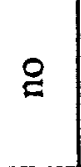 & 임 & \& & $\stackrel{\circ}{g}$ & ㅇ & 잉 & \\
\hline & $\dot{s}$ & 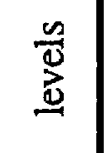 & $\begin{array}{l}m \\
\varrho \\
\varrho\end{array}$ & $\stackrel{m}{9}$ & $\infty$ & $\mid \begin{array}{c}\tilde{I} \\
\mathfrak{I}\end{array}$ & هُ & $\stackrel{\infty}{\infty}$ & $\begin{array}{l}\tilde{I} \\
\mathfrak{I}\end{array}$ & $\begin{array}{l}m \\
\sigma^{\circ}\end{array}$ & $\begin{array}{l}\stackrel{2}{2} \\
\stackrel{2}{2}\end{array}$ & 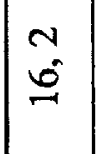 & $\begin{array}{l}+ \\
\dot{x}\end{array}$ & $\stackrel{\nabla}{q}$ & $\stackrel{m}{s}$ & $m$ & \\
\hline & $\exists$ & 㽞 & $\frac{N}{2}$ & $1-$ & 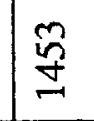 & $\stackrel{?}{\Xi}$ & 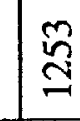 & $\underset{\Xi}{\stackrel{g}{2}}$ & 䆞 & 芯 & 总 & 总 & $\frac{\text { of }}{2}$ & 莣 & 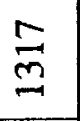 & \pm & \\
\hline & & 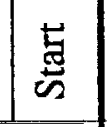 & స్తి & 89 & $\frac{\pi}{m}$ & 离 & $\exists$ & 然 & 兽 & $\bar{g}$ & $\bar{\Xi}$ & $\mid \frac{a}{2}$ & $\frac{m}{9}$ & $\stackrel{\circ}{\Xi}$ & $\grave{\Xi}$ & $\approx$ & \\
\hline & & 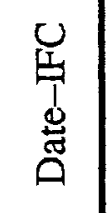 & 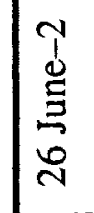 & & & त्र & 音 & & $\frac{1}{3}$ & $\mid \begin{array}{l}1 \\
\text { 家 } \\
\text { a }\end{array}$ & $\begin{array}{l}? \\
? \\
g \\
q \\
q\end{array}$ & $\mid \begin{array}{c}p \\
b \\
b \\
\frac{b}{2} \\
\sigma \\
\end{array}$ & 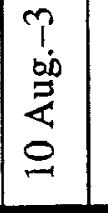 & & & 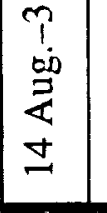 & \\
\hline
\end{tabular}




\begin{tabular}{|c|c|c|c|c|c|c|c|c|c|c|c|c|c|c|c|c|c|}
\hline$N$ & $m$ & $m$ & $\sim$ & $N$ & o & $\theta$ & $m$ & $m$ & $N$ & $m$ & $N$ & in & in & $m$ & m & $\sim$ & $\sigma$ \\
\hline$\vec{\sim}$ & $\mathbb{N}$ & $\approx$ & $\pi$ & $\vec{\lambda}$ & $\approx$ & $A$ & A & $\approx$ & $\stackrel{\infty}{\sim}$ & 2 & 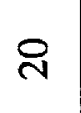 & 9 & 2 & $\overrightarrow{4}$ & $\vec{\pi}$ & $\vec{v}$ & \\
\hline 括 & $\vec{m}$ & $\vec{m}$ & & $\stackrel{\circ}{\circ}$ & $\nsubseteq$ & $\cong$ & in & $\stackrel{\infty}{్ ల ్}$ & $\underline{n}$ & 孞 & $\overrightarrow{\sigma^{\prime}}$ & $\vec{m}$ & $\stackrel{m}{m}$ & $\stackrel{\infty}{m}$ & 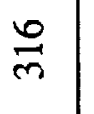 & 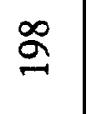 & \\
\hline 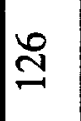 & $\beth$ & $\cong$ & $\check{x}$ & $\stackrel{\square}{\sigma}$ & $\mid$ & $\stackrel{\infty}{=}$ & | & $\approx$ & $\bar{\Xi}$ & 染 & $\ddot{d}$ & 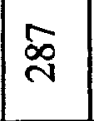 & $\mid \begin{array}{l}\infty \\
i\end{array}$ & 总 & $\frac{ \pm}{m}$ & $\stackrel{ \pm}{\Xi}$ & 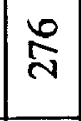 \\
\hline 过 & $\Xi$ & $\Xi$ & 8 & 5 & $\stackrel{\infty}{\varrho}$ & $\stackrel{\infty}{g}$ & ন & ల్ల & $\stackrel{8}{\circ}$ & 品 & 아 & $\tilde{z}$ & $\mathbb{Z}$ & 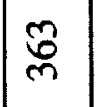 & $\vec{m}$ & 号 & $\frac{\partial}{\lambda}$ \\
\hline$\Xi$ & $\alpha$ & $\approx$ & 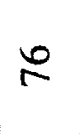 & 8 & 12 & $\Xi$ & $\approx$ & $\stackrel{ \pm}{ \pm}$ & $\vec{\Xi}$ & $\tilde{\mathrm{n}}$ & $\tilde{\Xi}$ & $\underline{5}$ & $\tilde{d}$ & శ్సి & ৪্ন & $\stackrel{9}{9}$ & $\exists$ \\
\hline 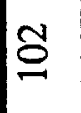 & $\infty$ & $\infty$ & 5 & $\Phi$ & $\infty$ & $\stackrel{\infty}{=}$ & i & $\stackrel{\leftrightarrow}{\circ}$ & $\underline{g}$ & $\tilde{\tilde{j}}$ & 8 & $\vec{n}$ & ๙̊ & 18 & $\stackrel{\overrightarrow{\mathbf{s}}}{\vec{\sim}}$ & $\approx$ & \\
\hline$\infty$ & $\infty$ & $\approx$ & $\tilde{n}$ & on & $=$ & $g$ & $\overline{\boldsymbol{N}}$ & 桌 & $m$ & $\frac{7}{4}$ & q & $\exists$ & $\cong$ & $\infty$ & 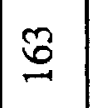 & $i n$ & $\stackrel{\infty}{\Xi}$ \\
\hline$\infty$ & $\approx$ & $\approx$ & q. & $\approx$ & $\infty$ & $\dddot{q}$ & 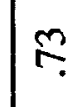 & $\underset{m}{\infty}$ & f. & $\vec{\infty}$ & $\Leftrightarrow$ & $\because$ & $\infty$ & $ळ$ & $\tilde{g}$ & $\mid \begin{array}{l}\infty \\
\infty\end{array}$ & $\left.\right|^{\infty}$ \\
\hline & $\because$ & $\because$ & 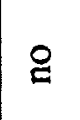 & 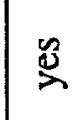 & $\frac{\mathscr{D}}{2}$ & 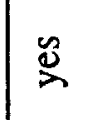 & $\stackrel{2}{2}$ & 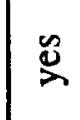 & $\ddot{\nu}$ & $\stackrel{\leftrightarrow}{\circ}$ & $\stackrel{\Delta}{2}$ & $\stackrel{2}{2}$ & $\underset{2}{\sim}$ & 总 & $\$$ & $\stackrel{0}{2}$ & $\$$ \\
\hline & $\begin{array}{l}\forall \\
\dot{ \pm}\end{array}$ & $\begin{array}{l}+ \\
\dot{J}\end{array}$ & $\stackrel{m}{\simeq}$ & $\begin{array}{l}+ \\
\infty\end{array}$ & هُ & $\stackrel{\infty}{\simeq}$ & 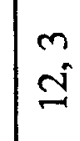 & $\stackrel{m}{a}$ & $\begin{array}{l}\infty \\
\infty \\
\infty\end{array}$ & $\begin{array}{l}m \\
\tilde{I}\end{array}$ & $\underline{m}$ & 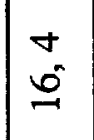 & $\mid \begin{array}{l}\stackrel{+}{0} \\
\stackrel{0}{\circ}\end{array}$ & $\begin{array}{l}n \\
\dot{ \pm}\end{array}$ & $\mid \begin{array}{l}m \\
0\end{array}$ & $\stackrel{N}{ }=$ & \\
\hline 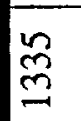 & g & 点 & $\overrightarrow{8}$ & 㞼 & $\mathbb{Z}$ & 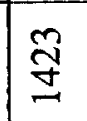 & $\tilde{\Xi}$ & 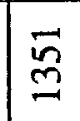 & 弟 & $\stackrel{\infty}{\nexists}$ & $\underline{0}$ & \begin{tabular}{|l} 
菏 \\
\end{tabular} & 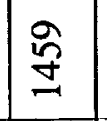 & 总 & 靑 & 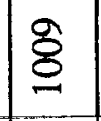 & $1=$ \\
\hline & స్తి & త్తి & $\stackrel{\vec{\Xi}}{\underline{\underline{a}}}$ & 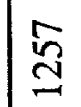 & $\simeq$ & $\sim$ & $\underline{2}$ & $1 \approx$ & n & İ & 害 & 12 & $\overrightarrow{\vec{m}}$ & 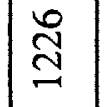 & 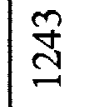 & 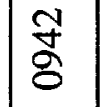 & \\
\hline 若 & 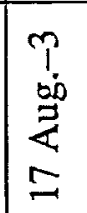 & 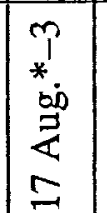 & 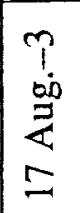 & 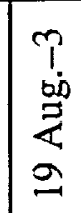 & & $?$ & $\begin{array}{c}T \\
\text { T. } \\
\text { g. }\end{array}$ & $\begin{array}{l}\frac{7}{4} \\
\overrightarrow{8}\end{array}$ & & 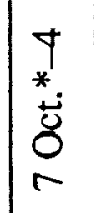 & $\mid \begin{array}{l}\nabla \\
*\end{array}$ & 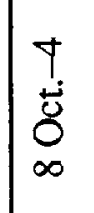 & & 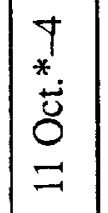 & & $\mid \begin{array}{l}T \\
\dot{\Delta}\end{array}$ & \\
\hline
\end{tabular}


I

응

肎

点

홍

8

๖ัّ 


\begin{tabular}{|c|c|c|c|c|c|c|c|c|c|c|c|c|c|}
\hline & & & & o & 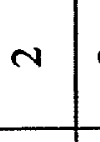 & & ${ }^{\circ} \mathrm{m}$ & $1+$ & $m$ & m & & $\checkmark$ & \\
\hline & & 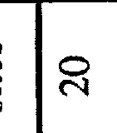 & & $=$ & 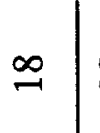 & $\therefore 8$ & 8 & I & $\simeq$ & $\therefore$ & $\vec{\sim}$ & 9 & $\bar{\lambda}$ \\
\hline \multirow{3}{*}{ E } & & 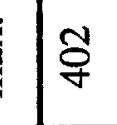 & 总 & $\sqrt[5]{8}$ & & $\vec{F}$ & $\check{~}$ & & & $d_{d}$ & $\tilde{i}$ & ఫ్తి & \\
\hline & 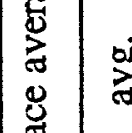 & 家 & : & 等 & 离 & $\underset{\infty}{\infty}$ & 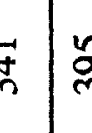 & $\bar{\sigma}$ & 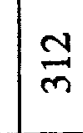 & 冞 & 总 & 壱 & 1) \\
\hline & 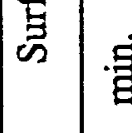 & 㡶 & $\overrightarrow{\tilde{m}}$ & $\ddot{q}$ & $\bar{m}$ & $\mathbb{e}$ & 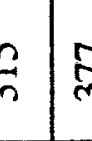 & 菏 & & $\frac{\infty}{\mathrm{A}}$ & : & 苦 & $1 \%$ \\
\hline & 它 & 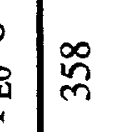 & F & $\mathscr{\mathscr { \sigma }}$ & $\overrightarrow{\mathrm{v}}$ & $\hat{n}$ & $\frac{6}{2}$ & $\tilde{z}$ & F & ळ్ & $\tilde{\tilde{N}}$ & ఫ్ & \\
\hline & & 屏 & $\approx$ ले & 离 & $\overrightarrow{\mathrm{a}}$ & 尊 & 8 & $\approx$ ป & & 5 & $\stackrel{\circ}{\circ}$ & $\Xi$ & 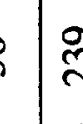 \\
\hline & & 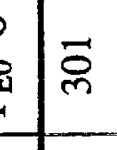 & $\underset{\sim}{\mathbb{\infty}}$ & 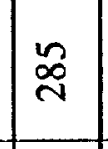 & $\stackrel{8}{\Omega}$ & $\vec{a}$ & & 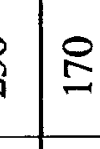 & & $\overline{\bar{c}}$ & $\underset{\sim}{2}$ & 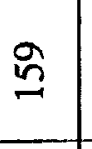 & \\
\hline & & ते & $\because$ & $\underset{?}{\infty}$ & 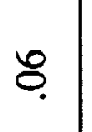 & $\tau$ & 8. & $\stackrel{\infty}{=}$ & 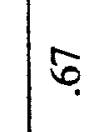 & \% & $\Xi$ & $\underset{f}{q}$ & \\
\hline & 总 & 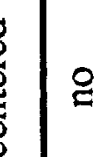 & 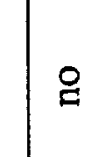 & $\cong$ & 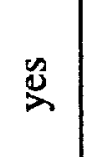 & 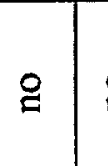 & 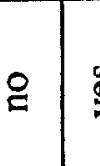 & 8 & $\because$ & $\because$ & $\because$ & $\cong$ & \\
\hline & & & & $\mid \begin{array}{l}a \\
\infty\end{array}$ & 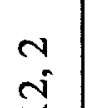 & 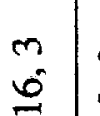 & $a_{\infty}^{2}$ & & & & $\mid \begin{array}{l}a \\
\dot{\Xi}\end{array}$ & & \\
\hline & & & & & & & & & & & 等 & & \\
\hline & & 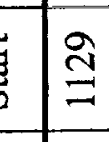 & 12 & & 12 & & & 219 & & & & $1=$ & \\
\hline & & & & & & & & & & & & & \\
\hline
\end{tabular}




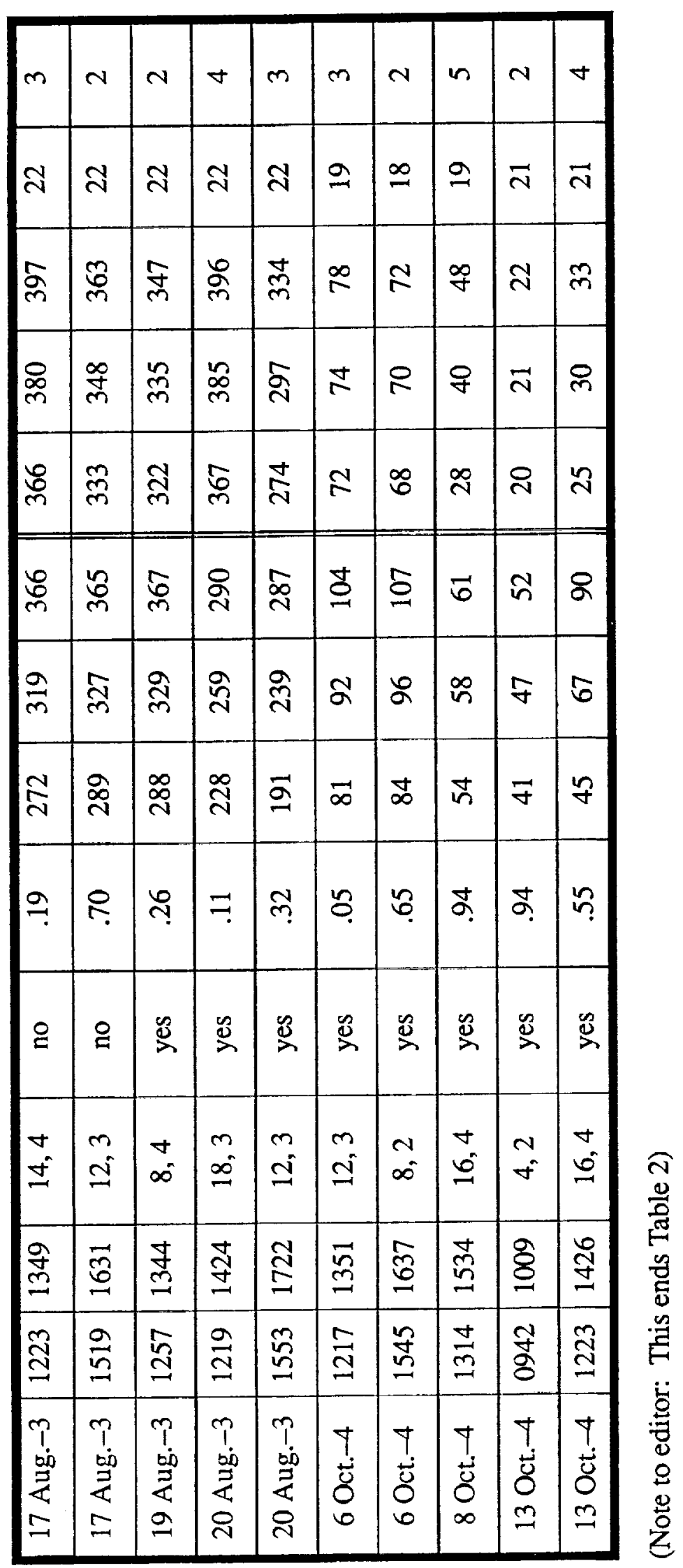




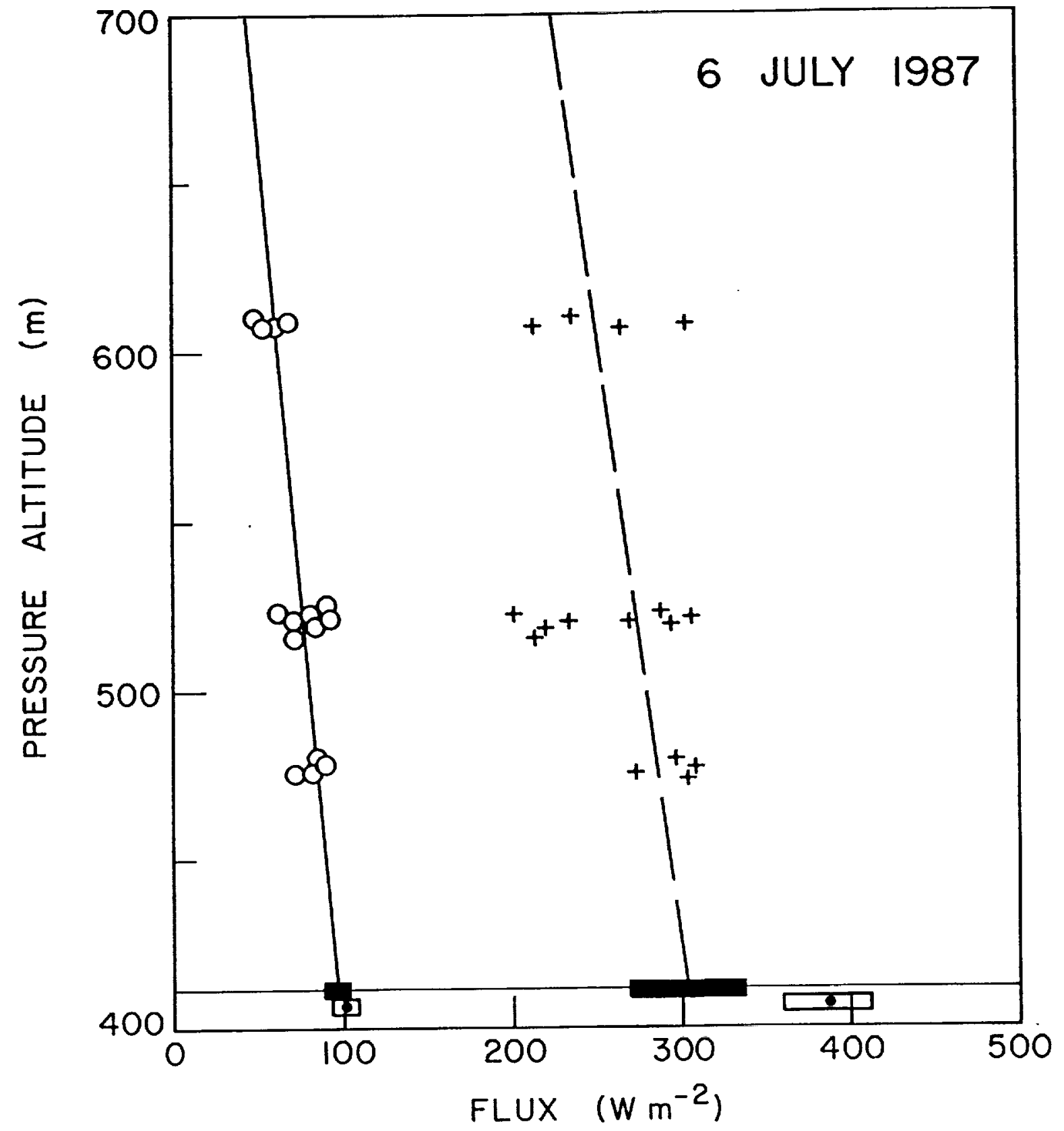

Fig. 1 


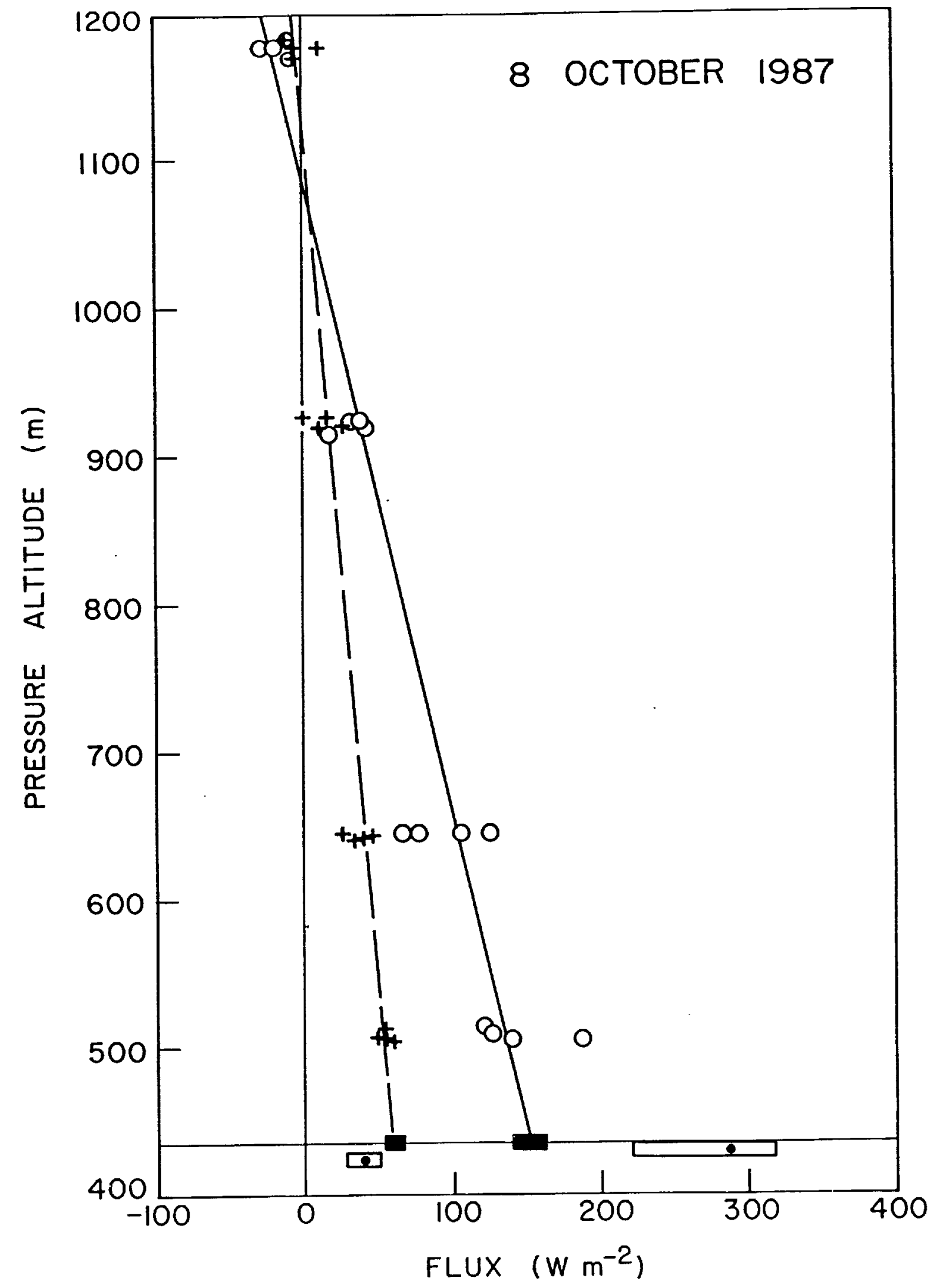

Fig. 2 


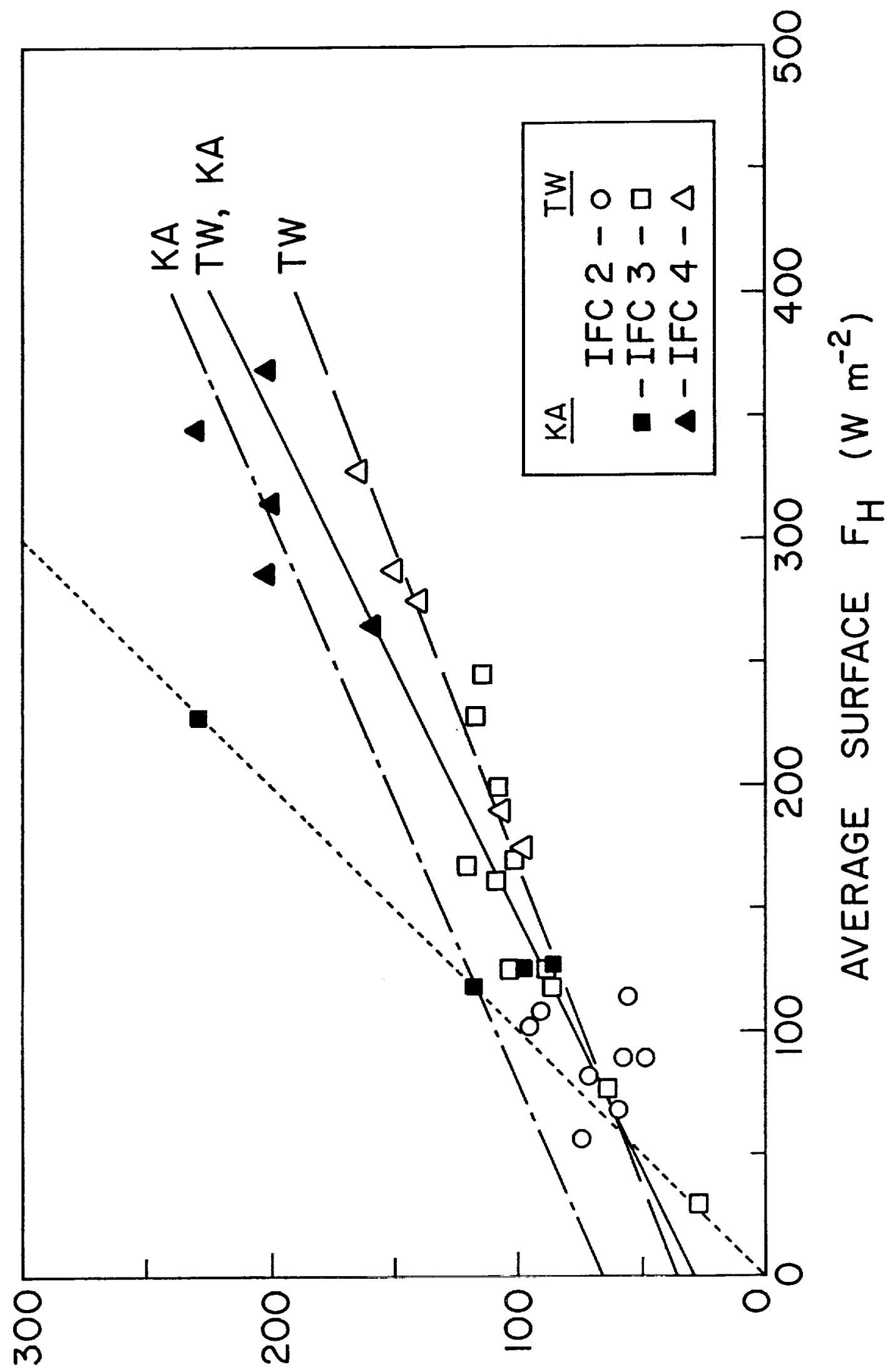

$m$ 它

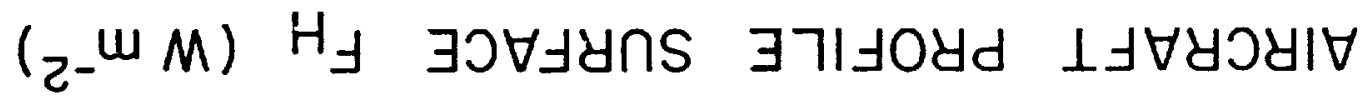




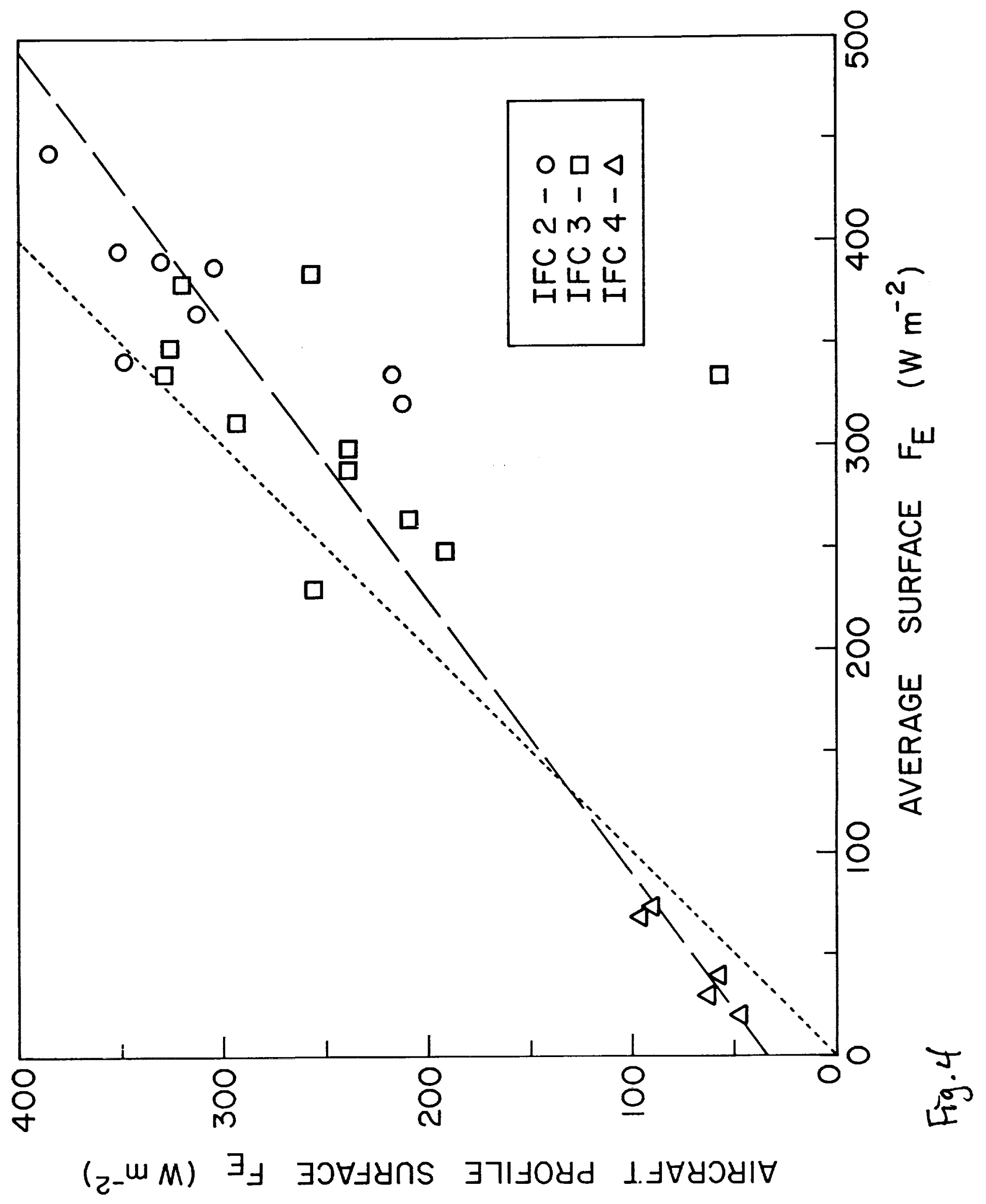

